from 3.30 p.m. until 4.55 p.m. (French time), and on the north and south at a considerable distance through the mist there appeared two ares of a circular halo, showing on the north colours from red to green, and on the south colours from red to yellow, only the other spectrum colours were absent.

About 4.30 p.m. a dark grey cloud hid the whole phenomenon, but about 4.45 p.m. until the end of the display the grey cloud passed, and the sight was both beautiful and brilliant.

The colour-bands were very wide; the green was the widest and palest, and I only observed it on the northern arc.

Bordeaux, September 28.

R. Ashington Bullen.

\section{RADIUM STANDARDS AND NOMENCLATURE.}

' $\mathrm{HE}$ International Congress of Radiology and Electricity, held at Brussels, September I th to I 5 th, afforded an excellent opportunity of discussing several important questions of general interest to workers in radio-activity. The need of a definite radium standard, in which all results should be expressed, has been growing more acute with the increase of accuracy of radio-active measurements. At the present time, scientific results are expressed in many cases in terms of arbitrary radium standards kept in each laboratory, and it has been difficult to be certain of the accuracy or relative value of such standards. Mr. C. E. S. Phillips several years ago pointed out to the Rüntgen Society the desirability of adopting a fixed radium standard, and arranged for the preparation of several small radium standards which were compared with the working standard adopted by Rutherford and Boltwood. Duplicates of the latter standard have been used for several years by a number of English, American, and Continental worlzers.

At the opening meeting, Prof. Rutherford read a report on the desirability of establishing an international radium standard. $\mathrm{He}$ pointed out that he had compared by the $\gamma$ ray method the radium standards used by several important European laboratories, and had found that there was a considerable difference amongst them, amounting in some cases to 20 per cent. It is now possible to measure with considerable precision a number of magnitudes connected with radium; for example, the volume of the emanation, the heating effect, the rate of production of helium, and the rate of emission of $\alpha$ and $\beta$ particles. The values of each of these quantities is dependent on the accuracy of the radium standard in which the results are expressed. For the comparison of results obtained by workers in different laboratories, it is necessary that thev should all be expressed in terms of the same standard. For example, at the present time it is not possible to compare the results obtained on the heat emission of radium by various observers until the radium standards employed have been accurately compared. When once a standard has been adopted, it is relatively a simple matter to determine the radium contents of substandards by the $\gamma$ ray method or modification of it, without opening the tube containing the radium.

A special international committee was appointed to report to the congress on the best means to be adopted to fix an international radium standard. This committee comprises the following workers in radio-activity representative of a number of countries : Mme. Curie, Debierne, Rutherford, Soddy, Hahn, Geitel, Mever, Schweidler, Eve, and Boltwood. No doubt representatives of other countries who are prepared to assist in the work will be added later. This NO. 2 I 36 , VOL. 84$]$ commictee reported to the congress at its final $\cdot$ meeting and their suggestions were adopted by the congress. As a member of the committee, Mme. Curie agreed to prepare a radium standard containing about 20 milligrammes of radium enclosed in a suitable sealed tube. This standard is somewhat large, but the amount was considered necessary on account of the difficulty of weighing small quantities of radium salt with the requisite accuracy. The thanks of all workers in this subject are due to Mme. Curie in undertaking the full responsibility of preparation of a standard, and for the large expenditure of time and labour its preparation will involve. The committee agreed to reimburse Mme. Curie for the cost of the radium and its preparation, after which the standard becomes the property, and is under the control, of the international committee. It was suggested that the standard should be suitably preserved in Paris. The initial cost of preparation of this standard will be somewhat heavy (about 5ool.), but it is hoped that scientific societies and Governments of various countries will assist in defraying the expenses.

As soon as the primary standard has been prepared, it is proposed to approach through the committee the various national laboratories. to ask them to acquire a radium standard accurately determined in terms of the primary standard. In this way it was thought that any Government interested in the question could acquire an accurate radium standard to be used as a basis for standardisation of quantities of radium in use in scientific laboratories, or to be sold commercially. As the primary standard is somewhat large for use in ordinary laboratories, the committee propose to investigate the question of the best method of comparing accurately in terms of the primary standard smaller substandards containing one or two milligrams of radium.

The committee also has under consideration the question of the preparation of very small substandards to be used for the determination of minute quantities of radium and of radium emanation. It is proposed that special investigations be made by the committee to determine the most suitable method of preparation and preservation of such standards. There is at present some uncertainty of how far radium solutions are affected by time in consequence of the tendency of radium to be precipitated out of the solution. No doubt before long it should be possible to secure accurate standard solutions to distribute amongst scientific workers.

In the course of the congress it was suggested that the name Curie, in honour of the late Prof. Curie, should, if possible, be employed for a quantity of radium or of the emanation. This matter was left for the consideration of the standards committee; the latter suggested that the name Curie should be used as a new unit to express the quantity or mass of radium emanation in equilibrium with one gram of radium (element). For example, the amount of emanation in equilibrium with one milligram of radium would be called I/ Inoo Curie or one millicurie. The adoption of this unit will avoid much circumlocution, and will prove useful since the radium emanation is now so widely used in all kinds of experiments.

The committee has under consideration the question whether special names should be given to a very small quantity of radium, and also to the emanation in equilibrium with it. For example, the quantity $I 0^{-12}$ gram radium seems a natural unit for expression of the radium content of rocks and soils. At the same time, the large amount of investigation on 
the emanation content of springs and waters may make it desirable to adopt a convenient unit for expression of such quantities.

The committee pointed out that its recommendations were tentative, as all the members of the standards committee were not present at the congress, and had no opportunity of expressing their opinions. It is intended that the preparation of the radium standard should be proceeded with as soon as possible, and it is hoped that the standardisation of substandards will be possible before a year has elapsed. Prof. Stefan Meyer, of the University of Vienna, was appointed secretary of the international committee, and all communications relative to standards should be addressed to him.

The question of the nomenclature of radio-active products was informally discussed at the congress. There was a general consensus of opinion that it was not desirable to alter materially the present system of nomenclature, although it was recognised that it is far from perfect. It was felt that the gain to be obtained by a possibly more systematic nomenclature was more than counterbalanced by the confusion that would arise in consequence of a change of names. It was pointed out that the present system of nomenclature was capable of extension to include possible new products. For example, if future investigation should disclose that the product radium $\mathrm{C}$ consists of several products these could be named radium $\mathrm{C}_{1}$, radium $\mathrm{C}_{2}$, radium $\mathrm{C}_{3}$, \&c., but the term radium $\mathrm{C}$ would be used generally to represent the group of products as they normally always occur together. Reference was made to the undesirability of individual workers assuming the right to give new and fancy names to well-known substances.

A number of suggestions in regard to general nomenclature in radio-activity and ionisation were also made to the congress. For example, it is proposed that the term "half-value period" should be used in all cases to represent the term required for a substance to be transformed to half its original value. It is suggested that the terms "induced" and "excited" activity should be abandoned and the term "active deposit" emploved in its stead, as reference is usually made to the radio-active matter itself and not to its radiations. There was a good deal of informal aiscussion amongst members as to the exact use of a number of scientific terms arising in radio-activity and allied subjects. Such discussions are of great importance in preventing unnecessary confusion in nomenclature due to the development of a rapidly growing subiect.

A more general account of the meetings and deliberations of the congress, prepared by Dr. Makower, will appear in another issue of Nature.

E. Rutherford.

\section{HEREDITY AT THE CHURCH CONGRESS.}

$T$ HE discussion on heredity and social responsibility at the meeting of the Church Congress at Cambridge showed clearly the growing appreciation of the importance of biological principles in the study of social phenomena. The debate was opened by a paper by Dr. G. E. Shuttleworth, who dealt with the subject of the feeble-minded, chiefly from the medical point of view. After tracing the history of the different methods of treatment, he pointed out that in the case of most of the feebleminded "there existed morbid heredity of a strongly transmissive character," and that the only sound process of attacking the problem was to be found in No. 2 I36, VOL. 84] segregating the rising generation of the feeble-minded in industrial colonies, apart from the general community, for in that way alone could the propagation of the evil be prevented by means in harmony with our feelings of humanity.

Mrs. Pinsent, of Birmingham, a member of the Royal Commission on the Feeble-Minded, gave a brilliant address, which was clearly the chief feature of the meeting. She produced the histories of several mentally defective families, in which disease, mental defect, and crime appeared generation after generation. She pointed out the cost of such families to the community, and the appalling waste of social effort involved in their supervision and maintenance. Good and useful families, themselves often with narrow means, were being taxed to support these degenerate folk, until the more efficient restricted their families under the growing economic pressure, and reduced expenditure on maintenance and education. Thus the unfit replaced the fit within our own civilisation and under our own eyes.

The crowded audience was clearly in sympathy with Mrs. Pinsent's view of the situation, and realised the dangers of ignoring any longer the increased chances of reproduction and survival which our modern humanitarian legislation and social action had given to the degenerate classes.

The Bishop of Ripon spoke on the declining birthrate, and said that, had it appeared in the less worthy elements of society it would have been welcome, but that, as it chiefly affected the better stocks of our race, it was deeply to be deplored. Especially was it disastrous from the point of view of the Empire, which could not hope to stand against other peoples, and especially against the increasing birth-rate, the growing numbers, and the improving organisation of the Eastern nations, unless our empty spaces in the Colonies were filled with men of British race. Marriage ought to be discouraged among the unfit, while the growth of the fit should be encouraged by a higher sense of duty in the homes and an imperial ideal of national life.

Mr. W. C. D. Whetham traced the part played by religion in the sociological development of society, and pointed out that it alone could give a motive strong enough to lead the mass of mankind to prefer the ultimate good of humanity to the immediate advantage of the individual. Hence religion possessed a real biological survival value, as Kidd showed in his bool on "Social Evolution." It followed that the National Church had a very great responsibility towards the race. To play its proper part, it must maintain its hold on the efficient families of the nation, and preach the duty of encouraging the rapid reproduction of the good stocks, while limiting the output of those defective in mind or body. The future belongs to those nations whose religious teachers realise this responsibility.

In the general discussion which followed, there was an almost unbroken agreement with the main point of view of the readers of papers. While one speaker thought that onlv 50 per cent. of mental defect could be traced to hereditv, and another emphasised the importance of alcoholism, there was a general consensus of opinion that the country must be awakened to the need of encouraging the growth of good stocks, and that the reproduction of the feebleminded nisust be prevented by legislative action.

The general effect of the meeting on the mind of the listener was to produce the belief that the Church Congress, at all events, was ready, in matters of social action, to "think biologically"-surely an encouraging sign. 